\title{
Vertebral Osteomyelitis in Broilers: A Review
}

http://dx.doi.org/10.1590/1806-9061-2017-0690

\section{Review}

\section{-Author(s)}

\section{Braga JFV!,II}

Martins NRS"I

Ecco R'

Departamento de Clínica e Cirurgia Veterinárias, Escola de Veterinária, Universidade Federal de Minas Gerais, Belo Horizonte, Minas Gerais, Brasil.

" Departamento de Ciências Animais, Centro de Ciências Agrárias, Universidade Federal Rural do Semi-árido, Mossoró, Rio Grande do Norte, Brasil.

II Departamento de Medicina Veterinária Preventiva, Escola de Veterinária, Universidade Federal de Minas Gerais, Belo Horizonte, Minas Gerais, Brasil.

\section{Mail Address}

Corresponding author e-mail address Roselene Ecco

Setor de Patologia. Departamento de Clínica e Cirurgia Veterinárias, Escola de Veterinária, Universidade Federal de Minas Gerais, Av. Antônio Carlos, 6627, Campus Pampulha, 30161-970, Belo Horizonte, Minas Gerais, Brasil.

Phone: +55 (31) 992023298

Email: eccoro.ufmg@gmail.com

\section{EKeywords}

Bacterial infections, Enterococcus spp. Enterococcus cecorum, locomotor diseases, poultry.

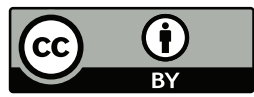

Submitted: 19/November/2017 Approved: 12/February/2018

\section{ABSTRACT}

Locomotor diseases are still a challenge in modern poultry. Vertebral osteomyelitis (VO) is an emerging disease in broilers worldwide. The inflammatory process in the affected thoracic vertebra (T4) and subsequent spinal cord compression leads to clinical signs related to locomotor impairment, inadequate feeding and drinking, and increased mortality in the affected flocks. The pathogenesis of the disease is poorly understood and Enterococcus cecorum is the bacterium most frequently associated with the disease. However, other bacteria such as E. faecalis, E. durans, Escherichia coli and Staphylococcus aureus have been recently detected in cases of the disease, raising questions regarding its etiopathogenesis. As many questions about $\mathrm{VO}$ in broilers remain unanswered, knowledge on its prevention, control and treatment is limited. In this review, we compile and discuss the currently available information concerning VO in broilers and highlight important aspects of the disease.

\section{INTRODUCTION}

Vertebral osteomyelitis (VO), also known as spondylitis, is an emerging disease that affects broilers worldwide (Devriese et al., 2002; Wood et al., 2002; Herdt et al., 2009; Aziz \& Barnes, 2009; Gingerich et al., 2009; Stalker et al., 2010; Kense \& Landman, 2011; Boerlin et al., 2012). Outbreaks of this disease have been found in broilers and broiler breeders and associated with infection by Enterococcus cecorum, which is a normal inhabitant of the chicken intestinal tract. VO is characterized by infection causing inflammation and necrosis of the free thoracic (T4) vertebral body. This results in spinal cord compression and impaired mobility of the affected broilers, which often die from dehydration or starvation (Aziz \& Barnes, 2007). The pathogenesis of the disease in chickens is still poorly understood (Martin et al., 2011), although some progress has been made in recent years. In addition to the impact on animal health, it is important to note that enterococci have emerged as an important cause of nosocomial infections, with drug-resistant microorganisms largely involved in these cases (McGaw, 2013). This review aimed at compiling and discussing the current knowledge on vertebral osteomyelitis in broilers, as well as relevant aspects related to this disease.

\section{Epidemiology of the disease}

VO has been reported in poultry in different European countries, such as the United Kingdon (Wood et al., 2002), The Netherlands (Devriese et al., 2002; Kense \& Landman, 2011), Belgium (Herdt et al., 2009), Hungary (Makrai et al., 2011), Norway (Kolbjørnsen et al., 2011), and Bulgaria (Dinev, 2013). The disease was also described in South Africa (Aitchison et al., 2014), Iran (Talebi et al., 2016) and some 
countries in North and South America, such as Canada (Stalker et al., 2010), several US states (Pennsylvania, Washington, North Carolina, South Carolina, Arkansas, Mississippi, Alabama, and California) (Aziz \& Barnes, 2009; Gingerich, 2009), and Brazil (Braga et al., 2016b).

According to some reports, the disease occurs more frequently in males (Aziz \& Barnes, 2007; Herdt et al., 2009; Aitchison et al., 2014) and may affect several strains (Wood et al., 2002; Gingerich, 2009). The higher body weight normally observed in males (Figure 1) implies an increase in the weight needed to be supported by bones and joints and a greater possibility of trauma. The influence of high body weight has also been described in another condition that affects broilers named bacterial chondronecrosis with osteomyelitis (BCO) by Wideman \& Prisby (2013).

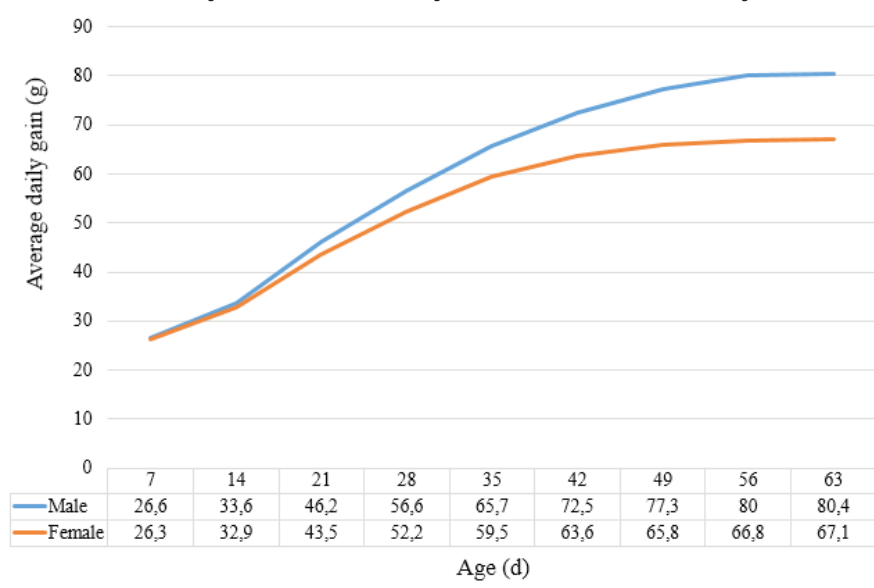

Figure 1 -Average daily weight gain $(\mathrm{g})$ of male and female broilers from seven to 63 days-old. Adapted from Cobb manual (2015).

The broilers affected by VO are usually older than 30 days-old, and outbreaks of the disease are reported between three to 18 weeks-old (Herdt et al., 2009; Armour et al., 2011; Robbins et al., 2012). However, there is a report in a flock as young as 15 days-old (Gingerich, 2009).

Predisposing factors for $\mathrm{VO}$ are not well defined (Kense\&Landman, 2011; Robbinsetal., 2012); however, immunosuppression and environmental conditions have been identified as factors that contribute to the occurrence of the disease (Stalker et al. , 2010; Armour et al., 2011). Any immunosuppressive condition can naturally predispose to opportunistic infection by $E$. cecorum, which is a normal intestinal commensal. However, a study demonstrated differences in the pathogenicity among commensal and clinical cases isolates, raising the question whether the emergence of clones is most likely the cause for the increased occurrence of infections (Boerlin et al., 2012).
Some evidences suggest that the higher incidence of enterococci-associated diseases in poultry may be due to horizontal spread of dominant $E$. cecorum clones that exhibit high pathogenicity (Kense \& Landman, 2011; Boerlin et al., 2012). However, the source of pathogenic $E$. cecorum remains unknown (Borst et al., 2017). Moreover, bacterial strains with genotypes similar to those isolated from $V O$ cases were rarely recovered from the ceca of birds with VO and the presence of these isolates was not statistically associated with a higher risk of disease (Borst et al., 2012). These findings suggest that the long-term cecal carrier state of pathogenic clones may not be required for the pathogenesis of VO caused by $E$. cecorum. However, as the disease has a chronic character, taking weeks from the time of infection until the onset of clinical signs, pathogenic strains may be transient in the gastrointestinal tract and therefore not recoverable in the moment of clinical presentation (Borst et al., 2012). Field observations showed that the disease occurred in successive flocks, suggesting the persistence of $E$. cecorum on the farm (Herdt et al., 2009; Kense \& Landman, 2011). According to Borst et al. (2017), persistence of $E$. cecorum in the environment between flocks is unproven, although the repeated outbreaks on affected farms may be associated to environmental contamination by pathogenic $E$. cecorum.

Despite their worldwide distribution, how pathogenic clones of $E$. cecorum spread remains undetermined. Epidemiological studies on different VO outbreaks suggest that mechanical spreading by biological vectors or inadequate biosafety may contribute to disease transmission, but horizontal transmission between geographically distant locations is considered unlikely (Borst et al., 2012).

Kense \& Landman (2011) demonstrated that vertical transmission does not occur. Recently, Borst et al. (2014) showed lower survival rate of SPF and non-SPF chicken embryos inoculated with $E$. cecorum isolated from vertebral lesions compared with those inoculated with $E$. cecorum isolated from the intestines of healthy birds. The embryos infected with pathogenic strains presented lesions of septicemia, such as hemorrhage and edema. In embryos inoculated with non-pathogenic strains, these lesions were found only 48 hours later.

\section{Etiology}

Enterococcus cecorum

Since 2002 , E. cecorum has been found to be the bacterium most often involved in outbreaks of non- 
vertebral and vertebral osteomyelitis and arthritis in broiler and broiler breeders (Aziz \& Barnes, 2007; Herdt et al., 2009; Aziz \& Barnes, 2009; Gingerich, 2009; Stalker et al., 2010; Martin et al., 2011; Boerlin et al., 2012; Aitchison et al., 2014).

Enterococcus spp. are gram-positive and spherical bacteria, which occur alone, in pairs or short chains. They are non-motile, non-spore-forming, facultative anaerobic with diverse biochemical properties (Wages, 1998). However, the relationship between the biochemical characteristics and pathogenicity of this genus remains unknown (Thayer et al., 2008). Enterococcus spp. are ubiquitous in nature, with worldwide distribution in avian species. They are considered part of the normal intestinal microbiota of chickens and commonly found in poultry environments. The frequency with different species of Enterococcus spp. are isolated from the intestinal tract of healthy birds may vary according to age, but only a limited number of species are commonly isolated. The species E. faecium, E. cecorum, E. faecalis, E. hirae and E. durans were regularly isolated in at least one of three different age groups ( 1 day-old, 3 to 4 weeks-old, and older than 12 weeks-old) examined by Devriese et al. (1991). Enterococci are also important as nosocomial pathogens that cause bacteremia, endocarditis and other infections. Some strains are resistant to many antibiotics and possess virulence factors, such as adhesins, invasins, hemolysin, and pili (Franz et al., 2011).

E. cecorum occurs more frequently in the intestines of chickens older than 12 weeks of age (Devriese et al., 1991) and has rarely been associated with clinical disease in these birds (Devriese et al., 2002; Wood et al., 2002; Chadfield et al., 2004; Thayer et al., 2008). This could explain the limited number of publications on its role in disease and its pathogenicity (Makrai et al., 2011). Two main hypotheses were proposed to explain the recent increase in the incidence of $E$. cecorum infections: 1) changes in the host or in environmental factors; and 2) emergence of individual clones with increased pathogenicity (Boerlin et al., 2012). In order to test the second hypothesis, those authors analyzed $E$. cecorum isolates recovered from the ceca of healthy chickens and those with VO by pulsed-field gel electrophoresis (PFGE). The E. cecorum genotypes isolated from the vertebral lesions were significantly more similar to each other than those isolated from the ceca of healthy birds and of birds with $\mathrm{VO}$, regardless of the affected broiler flock.
E. cecorum was also isolated from a broiler flock with pericarditis, hepatitis, femoral head necrosis and/ or VO and the authors concluded that bacteremia and generalized infection seem to be important steps in the pathogenesis of the infection caused by this bacterium in broilers (Jung \& Rautenschlein, 2014). This was also suggested by Borst et al. (2017), who observed that $E$. cecorum isolates recovered from the intestine, spleen, and free thoracic vertebra (FTV) of broilers in natural cases of VO had matching genotypes, confirming that intestinal colonization with pathogenic strains precedes bacteremia and infection of the FTV.

\section{Other etiologic agents}

Infections by $E$. hirae are relatively frequent in broilers, but its importance is not well understood. The incidence of diseases caused by this bacterium have increased in some countries, such as Norway, where $E$. hirae was isolated from cases of osteomyelitis in the proximal femur and endocarditis in broilers (Kolbjørnsen et al., 2011).

Braga et al. (2016b) recently reported E. hirae, E. faecalis, Escherichia coli, and Staphylococcus aureus in single or mixed culture from $\mathrm{VO}$ cases in broilers. $E$. coli, which has also been isolated from $V O$ cases in poultry (Dinev, 2013; Braga et al., 2016a; Braga et al., 2016b), is part of normal intestinal microbiota of humans and many animal species. $E$. coli is a gramnegative non-spore-forming bacillus, measuring 2-3x $0.6 \mu \mathrm{m}$, and most strains are motile with peritrichous flagella (Barnes et al., 2008).

Several E. coli strains are able to express virulence factors and cause intestinal or extra-intestinal diseases (Ambrozic et al., 1998). E. coli is currently considered the most important gram-negative bacterium in poultry due to its different pathogenicity mechanisms and described diseases (Nakazato et al., 2009). In avian species, E. coli pathogenic strains are named Avian Pathogenic Escherichia coli (APEC), which are responsible for extra-intestinal diseases generically known as colibacillosis (Ewers etal., 2004). The presence of $E$. coli in bone and synovial tissues is a common consequence of colisepticemia and the affected birds probably were not able to have completely eliminated the bacterial infection (Barnes et al., 2008).

Several virulence factors are associated with APEC, such as: $F 1$ and $P$ fimbrial adhesins, aerobactin iron acquisition system, $\mathrm{k} 1$ capsular antigen, complement resistance, and many proteins, such as Tsh autotransporter (Dho-Moulin \& Fairbrother, 1999). 
Staphylococcus pyogenes was isolated from VO cases in seven- to 16-weeks-old chickens (Carnaghan, 1966). Nairn (1973) reported the isolation of S. aureus from vertebral lesions in turkeys naturally affected with locomotor disorder, and that the experimental inoculation of turkeys resulted in osteomyelitis in the vertebral body and long bones. Van Veen (1999) detected the involvement of Aspergillus fumigatus in VO outbreaks in two flocks of 17- to 19-weeks-old broilers.

\section{Pathogenesis}

The pathogenesis of $\mathrm{VO}$ in birds remains largely unknown, although important progress has been made (Kense \& Landman, 2011; Robbins et al., 2012; Jung \& Rautenschlein, 2014; Borst et al., 2017). There are few publications on the pathogenicity of $E$. cecorum (Makrai et al., 2011) and the knowledge of the genetic basis for the recently acquired pathogenicity of certain E. cecorum strains and the pathogenesis of vertebral lesions characteristic of the disease remains limited (Borst et al., 2012; Borst et al., 2015).

Recent molecular epidemiologic studies found that pathogenic $E$. cecorum strains were genetically clonal and suggested acquisition of specific virulence determinants by pathogenic $E$. cecorum. This study also showed that pathogenic isolates had smaller genomes with a higher guanidine-cytosine (GC) content and large regions of synteny compared with commensal $E$. cecorum isolates. Molecular phylogenetic analysis demonstrated that, at a threshold of $98 \%$ identity, 414 predicted proteins were highly conserved in pathogenic $E$. cecorum but not in commensal strains (Borst et al., 2015).

A recent study compared pathogenic and nonpathogenic $E$. cecorum strains from different animal species. Pathogenic and commensal E. cecorum strains were not clearly separated from each other in a phylogenetic tree based on partial sequences of the 16S-rRNA-gene and their fatty acid profile. Also, it was noted that all pathogenic $E$. cecorum strains was not able to utilize mannitol, while $31.0 \%$ of the commensal strains were mannitol positive (Jung et al., 2017). This characteristic was also observed in other studies regarding the phenotypic and genotypic characterization of $E$. cecorum associated with infections in poultry (Dolka et al., 2016). Jung et al. (2017) did not find any significant difference in virulence factors between pathogenic and commensal isolates. On the other hand, mean embryo lethality of pathogenic $E$. cecorum isolates (39.7\%) was significantly higher than that of commensal strains (18.9\%). Those authors also reported that two different antisera were produced, although none of the serotypes were predominantly found either in pathogenic or commensal isolates.

Molecular studies on conserved genes to speciate enterococci suggested that pathogenic E. cecorum might be considered a subspecies in view of the divergence between commensal and pathogenic $E$. cecorum genomes (Borst et al., 2015). In addition, pathogenic strains showed conserved potential mediators of virulence, including genes encoding predicted collagen-binding proteins, a capsular locus, and orthologs to the enterococcal polysaccharide antigen of $E$. faecalis and $E$. faecium (Borst et al., 2015).

The disease was experimentally reproduced by Martin et al. (2011) by inoculating broilers with E. cecorum by oral and intravenous routes. Gross lesions were found five weeks after the experimental infection in $6.1 \%$ and $2.9 \%$ of the broilers orally and intravenously inoculated, respectively. However, histologic lesions were found in $30.3 \%$ of the orallyinoculated broilers, and the authors suggest that macroscopic evidence of disease would be greater if the broilers were older.

The FTV (T4) body is singly affected in VO and the reasons for this predilection are not fully understood. The FTV articulation is located between the immediately anterior fused thoracic vertebrae and the posterior synsacrum (Figure 2), enabling body position adjustments and flexibility during walk and flight, and is subject to greater biomechanical stress and microtraumas than any other vertebra. Excessive stress may lead to changes in blood flow, with the development of microthrombi, sequestrum and multiplication of bacteria present in the blood (Aziz \& Barnes, 2007; Stalker et al., 2010; Wideman \& Prisby, 2013; Aitchison et al., 2014). This corroborates with a recent study reporting that broilers with osteochondrosis dissecans (OCD) were more susceptible to VO development than birds with no FTV lesions, and that suggested that intestinal colonization, bacteremia, and OCD of the FTV in early life are crucial to the pathogenesis of the disease (Borst et al., 2017).

According to Stashak \& Mayhew (1984), VO is usually secondary to the hematogenous dissemination of a microorganism. However, other theories have been proposed to explain how the bacteria reach the FTV. One of these theories suggests that the agent has access to the bones via bloodstream due to disruption of the intestinal mucosal barrier (Stalker et al., 2010; Martin et al., 2011), as occurs in coccidiosis or bacterial enteritis (Gingerich, 2009). According to Martin et al. (2011), any factor that negatively interferes with intestinal health or disturbs intestinal microbiota 




Figure 2 - Pneumatization of the vertebral column in the chicken (Gallus gallus). Pneumatic vertebrae are represented by grey (upper diagram) or black (lower diagram). The vertebral column is pneumatized by cervical diverticula and abdominal air sacs and lungs. Adapted from Wedel (2007).

balance may predispose broilers to the systemic dissemination of $E$. cecorum. On the other hand, Borst et al. (2017) observed that clinical intestinal disease was not required to cause $E$. cecorum bacteremia.

A possible link of the $\mathrm{VO}$ with air sacs and pneumatic vertebra could exist (Aziz \& Barnes, 2007). However, the pneumatization of the vertebra where the disease occurs (T4) begins only after eight weeks of age (Figure 2 ). The experimental inoculation of $E$. cecorum in twoweeks-old broilers by air sac route did not result in VO (Martin et al., 2011), suggesting that older broilers should be inoculated for experimental studies. In a study conducted by Tankson et al. (2002), E. faecalis, $E$. durans, and $E$. coli were isolated from the heart and lungs in $15 \%$ of healthy chicks. However, there are no studies that provide this information for E. cecorum.

Some aspects of the pathogenesis of BCO may aid the understanding of $\mathrm{VO}$ pathogenesis. This disease commonly affects the femur and the tibiotarsus, but it may affect the FTV. BCO begins with the degeneration and necrosis of the cartilage, followed by bacterial invasion, and it is mainly associated with $S$. aureus, $E$. coli and E. cecorum, often in mixed infections, as well as with other bacteria (Wideman \& Prisby, 2013). Also, a recent study (Borst et al., 2017) demonstrated that pathogenic $E$. cecorum was observed within OCD lesions in the FTV in 1- to 3-weeks-old broilers with VO, and suggested that intestinal colonization, bacteremia, and OCD of the FTV in early life seem to be crucial for the pathogenesis of $\mathrm{VO}$.

It is believed that the BCO begins with mechanical damage to the poorly-mineralized columns of chondrocytes present mainly in the proximal growth plate of fast-growing bones, such as the femur and tibia, and is followed by the colonization of the chondronecrotic clefts by opportunistic hematogenous bacteria (Carnaghan, 1966; McNamee \& Smyth, 2000; Dinev, 2009; Wideman Jr et al., 2012), which was recently described in VO cases by Borst et al. (2017). Terminal BCO presents itself as degeneration, necrosis and bacterial infection at the proximal ends (epiphyseal and metaphyseal growth plates) of the femur and tibiotarsus. A similar process may occur in the growth plates of other bones that are subject to severe torque and shear stresses, as occur in the FTV, which functions as a flexible pivot between the cranially-fused vertebrae of the notarium and the caudally-fused vertebrae of the synsacrum (Carnaghan, 1966; McNamee \& Smyth, 2000; Dinev, 2009; Wideman Jr et al., 2012).

According to Barnes et al. (2008), the involvement of E. coli in infectious processes of the bone and synovial tissues is a common consequence of colisepticemia. Osteomyelitis caused by the hematogenous spread of $E$. coli after infection by the hemorrhagic enteritis virus was experimentally reproduced in turkeys (Droual et al., 1996). Some authors report that, although the intravenous inoculation of $E$. coli promoted its hematogenous spread to the bones and joints and reproduction of lesions, bird mortality caused by initial sepsis is usually high (Bayyari et al., 1997). According to Bayyari et al. (1997), that bacterium colonizes the vascular branches that invade the growth plate of growing bones, causing an inflammatory response that results in osteomyelitis. The transphyseal vessels in birds may possibly serve as conduits for the spread of bacteria to the joint and surrounding soft tissues.

\section{Clinicopathological changes}

\section{Clinical signs}

The clinical signs are similar in all VO cases reported (Gingerich, 2009), although the age of onset of clinical presentation may vary. In cases of osteomyelitis and arthritis caused by E. cecorum, Herdt et al. (2009) reported that the clinical signs started in the first and second weeks of age, with a mortality rate of $7 \%$. In the osteomyelitis cases studied by Makrai et al. (2011), the clinical signs started between 5-9 weeks up to 
10-13 weeks of age, with a mortality rate ranging from $8 \%$ to $30 \%$, which was higher than previously reported (Wood et al., 2002; Herdt et al., 2009).

The major clinical sign observed is the limited mobility, with birds presenting mild to severe lameness. The affected birds frequently acquire the posture described as "sitting on their hocks", characterized by cranially extended legs and support given by the tibiotarsus-metatarsus joints (Figure 3a) (Gingerich, 2009; Braga et al., 2016b). This is considered the classic clinical presentation of the disease, which is similar to that observed in birds with spondylolisthesis (Wood et al., 2002; Gingerich, 2009).

Severely affected broilers may remain in lateral recumbency (Gingerich, 2009). They occasionally use their wings to help locomotion, which may result in wing laceration and hematomas (Makrai et al., 2011). One of the consequences of impaired locomotion is the difficulty to access water and feed, resulting in reduced growth rate and ultimately in death due to dehydration or starvation (Barnes et al., 2008; Borst et al., 2017).

\section{Gross changes}

The macroscopic examination of the thoracolumbar region of vertebral column of the affected broilers reveals gross changes in the FTV (T4), characterized by a palpable whitish to yellowish enlargement (Figure 3b). The sagittal section of this lesion shows caseonecrotic material inside the vertebral body characterized by yellow to gray, granular and friable exudate, which is surrounded by a thick whitish capsule of fibrous connective tissue (Figure 3b, inset) (Gingerich, 2009; Martin et al., 2011; Robbins et al., 2012, Braga et al., 2016b). The most pronounced lesion is characterized by the increased size of the vertebral body as a result of infection, which results in narrowing of the overlying spinal canal and compression of the spinal cord (Makrai et al., 2011; Aitchison et al., 2014, Braga et al., 2016b). In the early stages of the disease, there is no obvious increase of the vertebral body and spinal compression of the sagittal section is absent or mild. The body condition of the affected birds varies from good to cachectic (Braga et al., 2016b).

\section{Histopathology}

The microscopic changes of VO observed with the experimental reproduction of the disease by $E$. cecorum infection were detailed by Martin et al.(2011) and were similar to those reported in natural cases of the disease (Stalker et al., 2010; Robbins et al.,
2012; Aitchison et al., 2014, Braga et al., 2016b). On the histopathologic examination, the FTV body and occasionally the adjacent vertebrae of notarium and synsacrum, presented necrotic tissue and exudate composed of fibrin, hemorrhage, and heterophils (Figure $3 e$ and 3f). The bone tissue that forms the basis of the spinal canal is replaced by fibrous connective tissue and exudate, leading to spinal canal stenosis and spinal cord compression. In addition, there is fibrous connective tissue proliferation and bone remodeling in the areas surrounding the lesion. There are also areas of bone and cartilage tissue sequestrum within the exudate. When bacterial colonies are present (Figure $3 e$, inset), they are numerous and associated with the sequestrated areas (Aitchison et al., 2014; Braga et al., 2016b). In addition to these changes, Aitchison et al. (2014) and Braga et al. (2016b) described reactive osteoid formation and cartilaginous metaplasia in the areas where there was severe thickening of the vertebral body, resulting in areas of spinal cord compression. In these areas, there was axonal loss and degeneration, and the neuropil was disorganized and vacuolated, indicating a compressive effect.

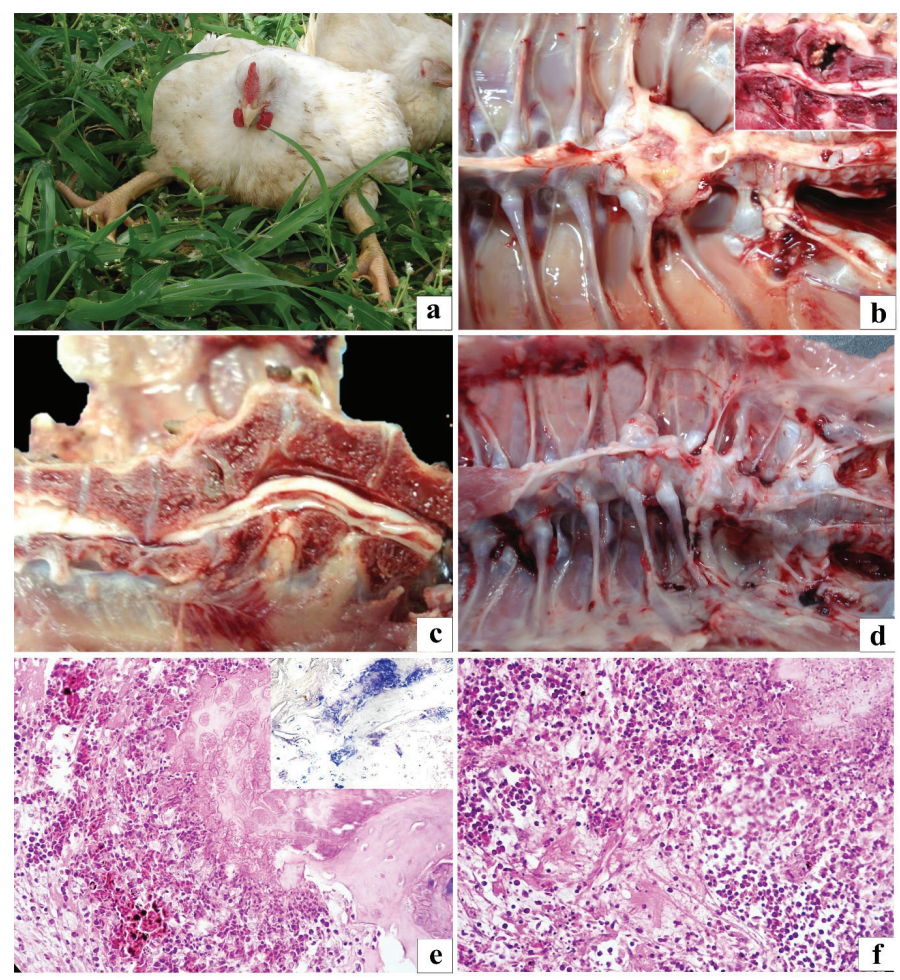

Figure $\mathbf{3}$ - Clinicopathological changes of vertebral osteomyelitis and differential diagnosis in the broilers. (a) A broiler presenting the classical clinical sign of vertebral osteomyelitis. (b) Gross changes in the vertebral osteomyelitis showing enlargement of affected vertebral body (T4). Inset: sagittal section with caseonecrotic material in the T4 vertebra and spinal cord compression. (c) Displacement of T4 vertebral body, characteristic of spondylolisthesis with spinal cord compression. (d) Scoliosis characterized by lateral deviation of vertebral column. (e, f) Histological changes of vertebral osteomyelitis. Necrotic tissue, cell debris, heterophils, hemorrhage, and fibrin are present. HE stain, bar $=50 \mu \mathrm{m}$. Inset: Gram-positive bacteria associated with vertebral lesion. Goodpasture stain, bar $=50 \mu \mathrm{m}$ 
Martin et al. (2011) reported histologic changes in broilers in the absence of macroscopic lesions, including mild histologic lesions in the subchondral vertebral areas, with no extension to the articular cartilage or adjacent vertebrae. Moderate to severe lymphocyte infiltration and diffuse fibroplasia in the affected vertebra with intralesional bacteria was confirmed in half (4/8) of the cases. Braga et al. (2016b) detected also lesions in adjacent vertebrae, characterized by degeneration and necrosis of the articular cartilage (T4/ T5), and occasional presence of clefts associated or not with hemorrhages and bacterial colonies. In the study of Martin et al. (2011), osteochondrosis was present in all birds, some of which presenting different degrees of subluxation FTV. A recent study on $\mathrm{VO}$ pathogenesis also described histologic lesions consistent with OCD, characterized by variably large cartilaginous clefts, which were often partially to completely filled with thrombocytes, fibrin, and erythrocytes. In some cases, there were cocci consistent with $E$. cecorum colonizing some of these clefts (Borst et al., 2017).

\section{Diagnosis}

VO may be suspected in birds sitting on their hocks (McNamee \& Smyth, 2000). It should be emphasized that high-quality veterinary support and thorough pathological and bacteriological examinations are indispensable for the early diagnosis of $\mathrm{VO}$ in broiler flocks. This is essential for the success of antibiotic therapy in the early stages of the disease (Jung \& Rautenschlein, 2014).

Broilers presenting locomotor disorders should be placed in orthostatic (standing) position and encouraged to move to assess gait and posture changes. These birds should be then euthanized and necropsied to examine possible gross changes in the locomotor system (axial and appendage skeleton), and the vertebral column sectioned along the longitudinal midline to examine the vertebral body and assess the degree of spinal cord compression (Gingerich, 2009; Braga et al., 2016b). At necropsy, samples for bacterial isolation and identification, polymerase chain reaction (PCR) tests, and histopathology should be collected.

For bacterial culture and isolation, swabs from caseonecrotic material of vertebral lesions should be aseptically collected and inoculated onto blood agar (BA) and MacConkey agar. It is recommended to incubate one BA plate under microaerophilic conditions $\left(37^{\circ} \mathrm{C}, 24\right.$ to $72 \mathrm{~h}$ ) and the other plates under aerobic conditions at the same temperature and time to enable the isolation of different etiologic agents (Braga et al., 2016b). After initial bacterial growth, the colonies must be Gram stained and submitted to catalase and oxidase tests. Bacterial isolates may be identified by biochemical tests, rapid ID 32 STREP (BioMerieux), VITEK 2 system (bioMérieux), and MALDI-TOF (AXIMA Assurance).

For DNA detection of the etiologic agent, vertebral lesion samples should be collected in sterile microtubes and frozen at $-20^{\circ} \mathrm{C}$ for DNA extraction and subsequent PCR testing. A multiplex PCR assay was described to enable the detection of different species of Enterococcus sp. (Jackson et al., 2004). Recently, Jung et al. (2017) reported the use of a newly-developed quantitative TaqMan real-time PCR (qPCR) assay based on the 16SrRNA-gene for the detection of E. cecorum. According to those authors, this new $\mathrm{qPCR}$ is highly specific, more sensitive than classical cultivation, and was able to determine colonization differences between a broiler flock presenting a late outbreak of $E$. cecorum disease compared to a healthy flock.

After sample collection for bacteriology and PCR, vertebral columns with gross lesions must be preserved in 10\% neutral buffered formalin (48 to $72 \mathrm{~h}$ ) for histopathological analysis. Vertebral columns should be decalcified in $24 \%$ formic acid before routine histological processing. The slides should be stained with hematoxylin-eosin and Goodpasture stains (Luna, 1968) to search for VO characteristic lesions (previously described in the histopathology subsection) and intralesional bacteria under a light microscope (Braga et al., 2016b).

The differential diagnosis of $\mathrm{VO}$ includes other pathologies that may cause spinal cord compression or changes in nerves causing impaired mobility. One of these conditions is spondylolisthesis ("kinky back"), characterized by subluxation of the FTV (Armour et al., 2011; Robbins et al., 2012). Grossly, these cases show varying extents of ventral dislocation of the FTV, whose posterior end raises the $5^{\text {th }}$ thoracic vertebra. The dislocation may produce kyphotic angulation of the spinal canal and varying degrees of spinal cord compression (Figure 3c). Necrotic and inflammatory lesions of the vertebral body in broilers with spondylolisthesis may not be present (Dinev, 2012). Scoliosis characterized by lateral deviation of the spine (Figure $3 \mathrm{~d}$ ) should also be considered for differential diagnosis of the aforementioned conditions (Droual et al., 1991). Proper monitoring of the flock may aid the early detection of these conditions, facilitating their diagnosis (Gingerich, 2009). Birds with the paralytic or the neurological form of Marek's disease may present clinical signs similar to VO and it should be considered 
in differential diagnosis. In Marek's disease, no changes in the vertebral column are observed, but there is enlargement of peripheral nerves, which become greyish or yellowish with loss of striations, acquiring an edematous appearance in some cases (Schat \& Nair, 2008).

\section{Prevention, treatment and control}

Information on prevention, treatment and control of the disease is limited, as the etiopathogenesis of VO remains unclear (Aitchison et al., 2014), and most studies are related only to infections caused by $E$. cecorum. For the prevention of $\mathrm{VO}$, recommendations on management practices to reduce the risk of developing the disease have been made, such as: 1) avoiding excessive feed restriction; 2) following the suggested weight gain standards and nutritional recommendations (Martin et al., 2011); 3) promoting adequate control of coccidiosis (Stalker et al., 2010); 4) avoiding high housing density; 5) ensuring adequate access to feeders; and 6) preventing respiratory diseases (Aitchison et al., 2014). All practices to prevent bacterial infections that may cause bacteremia would probably also help to avoid bone and articular inflammation.

Antibiotics have been used to treat the bacterial infection in VO. Although several antibiotics have shown efficacy against the commonly described bacteria, it is difficult to achieve adequate concentrations of the antibiotics in the vertebral column. In the reported outbreaks of the disease, antibiotics were ineffective in reducing mortality possibly due to the inability of the antibiotic to effectively penetrate the anatomical areas where the bacterium is located or antimicrobial resistance of E. cecorum (Kense \& Landman, 2011). The antimicrobial susceptibility profiles of $E$. cecorum isolated from outbreaks in different countries were similar (Herdt et al., 2009; Aitchison et al., 2014). Aitchison et al. (2014) reported that, after isolation and identification of $E$. cecorum, it was difficult to perform the antibiotic susceptibility test due to the growing conditions of the bacterium. Makrai et al. (2011) reported that, after the onset of the outbreak, broilers presenting clinical signs were separated from those clinically normal and the clinically normal were treated with different antibiotics (amoxycillin, amoxycillin with clavulanic acid, lincomycin or doxycycline), resulting in no new clinical case of the disease in the flock.

After the occurrence of the disease, the prevention of new cases requires repeated cycles of disinfection and usually occur after a single cleaning and disinfection procedure. Increased efforts in subsequent flocks are required to eliminate the disease. Some practices that may reduce the risk of $\mathrm{VO}$ in subsequent flocks include: 1) emptying and completely disinfecting the broiler house; 2) changing or composting the litter; 3) adequate cleaning of water lines; and 4) continuously sanitizing the water (Gingerich, 2009; Stalker et al., 2010; Armour et al., 2011; Martin et al., 2011).

\section{Antimicrobial resistance and public health}

As previously mentioned, enterococci are normal bacteria of the gastrointestinal tract of animals and humans and are often considered as beneficial commensal organisms (Tannock, 1995). However, they may also be opportunistic pathogens, responsible for serious systemic infections and for the spread of antimicrobial resistance and virulence determinants (Wisplinghoff et al., 2004; Heuer et al., 2006). In recent years, enterococci have emerged as a major cause of nosocomial infections, particularly E. faecalis (Kola et al., 2010), causing extraintestinal infections in humans (Creti et al., 2004). These bacteria have intrinsic resistance to many antibiotics and have acquired new resistance genotypes, out of which vancomycinresistant enterococci (VRE) are of special concern (Cetinkaya et al., 2000; Willems \& Bonten, 2007). VRE have become a major problem in nosocomial infections. A retrospective study of ten human patients with osteomyelitis showed that eight cases were due to infection by $E$. faecalis resistant to vancomycin, with one death reported due to bacteremia (Holtom et al., 2002).

The contamination of animals and their by-products by resistant bacteria and their possible foodborne transmission to humans are an animal and public health concern (Foulquié-Moreno et al., 2006). Enterococci may not only contaminate raw meat, but may also be present in processed meat products, such as cured raw sausages or cooked products (Martin et al., 2005; Barbosa et al., 2009; Ruiz-Moyano et al., 2009). Although no food poisoning associated with $E$. faecalis has been described in humans, a recent study performed in Brazil showed the presence of this bacterium in $42 \%$ of the chicken carcasses tested (Campos et al., 2013). All strains were resistant to at least one of the antibiotics tested, with the detection of the antimicrobial resistance genes $\operatorname{erm}(B)$, van $C-1$, aph(3')-IIla, ant(6)-la, vanB, vanA, aac(6')-le-aph(2")-la, erm(A)e tet(M). The relevance of $E$. faecalis in public health is also highlighted by its ability to transfer antimicrobial resistance genes to other organisms present in the intestinal tract of humans and animals, limiting the utilization of antibacterial drugs (Campos 
et al., 2013). Hayes et al. (2003) analyzed 981 raw meat samples of various species (chicken, turkey, swine and bovine) obtained in grocery stores and isolated 1,357 Enterococcus spp. strains, including E. faecalis (29\%) and E. hirae (5.7\%). Those authors also detected gentamicin resistance in $4 \%$ of the strains, most of which isolated from chicken meat. Braga et al. (2017), analyzing E. faecalis isolates from $\mathrm{VO}$ in broilers, demonstrated that the highest level of antibiotic resistance was against aminoglycosides, particularly gentamicin (40\%).

\section{CONCLUSION}

VO is an emerging disease in poultry worldwide that still needs to be further elucidated. Many aspects of the etiopathogenesis of the disease remain unclear, limiting its prevention and control. Most reports associate the disease to the infection by $E$. cecorum, probably related to emerging clones with higher pathogenicity. However, other bacteria have been isolated from VO in broilers, raising questions about the etiology and pathogenesis of the disease. This highlights the need for isolation and identification of the etiologic agent in cases of VO, as well as studies for molecular characterization and antimicrobial resistance of the involved bacterium.

\section{ACKNOWLEDGMENTS}

J.F.V. Braga was a fellow of the Programa de Pósgraduação em Ciência Animal/Universidade Federal de Minas Gerais supported by Coordenação de Aperfeiçoamento de Pessoal de Nível Superior (CAPES). Financial support was provided by Conselho Nacional de Desenvolvimento Científico e Tecnológico (CNPq) under Grant number 14/2010. We also are thankful to Pró-Reitoria de Pesquisa da Universidade Federal de Minas Gerais.

\section{REFERENCES}

Aitchison H, Poolman P, Coetzer M, Griffiths C, Jacobs J, Meyer M., Bisschop S. Enterococcal-related vertebral osteoarthritis in South African broiler breeders: A case report. Journal of the South African Veterinary Association 2014;85(1):1-5.

Ambrozic J, Ostroversnik A, Starcic M, Kuhar I, Grabnar M, Zgur-Bertok D. Escherichia coli Co IV plasmid pRK100: genetic organization, stability and conjugal transfer. Microbiology 1998;144(2):343-352.

Armour NK, Collet SR, Williams SM. Enterococcus cecorum- related arthritis and osteomyelitis in broilers and broiler breeders. The Poultry Informed Professional 2011:117:1-7.

Aziz T, Barnes HJ. Is spondylitis an emerging disease of broilers? World Poultry 2007;23:44-45.
Aziz T, Barnes HJ. Spondylitis is emerging in broilers.World Poultry 2009;25:14

Barbosa J, Ferreira V, Teixeira P. Antibiotic susceptibility of Enterococc isolated from traditional fermented meat products. Food Microbiology 2009;26(5):527-532

Barnes HJ, Vaillancourt JP, Gross WB. Colibacillosis. In: Saif YM, Fadly AM, Glisson JR, McDougald LR, Nolan LK, Swayne DE, editors. Diseases of poultry. $12^{\text {th }}$ ed. Ames: Blackwell Publishing; 2008. p.631-656.

Bayyari GR, Huff WE, Rath NC, Balog JM, Newberry LA, Villines JD, et al. Immune and physiological responses of turkeys with green-liver osteomyelitis complex. Poultry Science1997;76(2):280-288.

Boerlin P, Nicholson V, Brash M, Slavic D, Boyen F, Sanei B, et al. Diversity of Enterococcus cecorum from chickens. Veterinary Microbiology 2012;157(3-4):405-411.

Borst LB, Suyemoto MM, Keelara S, Dunningan SE, Guy JS, Barnes HJ. A chicken embryo lethality assay for pathogenic Enterococcus cecorum. Avian Diseases 2014;58(2):244-248.

Borst LB, Suyemoto MM, Robbins KM, Lyman RL, Martin MP, Barnes HJ. Molecular epidemiology of Enterococcus cecorum isolates recovered from enterococcal spondylitis outbreaks in the southeastern United States. Avian Pathology 2012;41(5):479-485.

Borst LB, Suyemoto MM, Sarsour AH, Harris MC, Martin MP, Strickland JD, et al. Pathogenesis of enterococcal spondylitis caused by Enterococcus cecorumin broiler chickens. Veterinary Pathology 2017;54(1):61-73.

Borst LB, Suyemoto MM, Scholl EH, Fuller FJ, Barnes HJ. Comparative genomic analysis identifies divergent genomic features of pathogenic Enterococcus cecorum including a type IC CRISPR-Cas system, a capsule locus, an epa-like locus, and putative host tissue binding proteins. PLoSOne 2015;10(4):e0121294.

Braga JFV, Chanteloup NK, Trotereau A, Baucheron S, Guabiraba R, Ecco R, et al. Diversity of Escherichia coli strains involved in vertebral osteomyelitis and arthritis in broilers in Brazil. BMC Veterinary Research 2016a;12(1):1-12.

Braga JFV, Leal CAG, Silva CC, Fernandes AA, Martins NRS, Ecco R. Genetic diversity and antimicrobial resistance profile of Enterococcus faecalis isolated from broilers with vertebral osteomyelitis in Southeast Brazil. Avian Pathology 2017;24:1-27

Braga JFV, Silva CC, Teixeira MPF, Martins NRS, Ecco R. Vertebral osteomyelitis associated with single and mixed bacterial infection in broilers. Avian Pathology 2016b;45(6):640-648.

Campos ACFB, Souza NR, Silva PHC, Santana AP. Resistência antimicrobiana em Enterococcus faecalis e Enterococcus faecium isolados de carcaças de frango. Pesquisa Veterinária Brasileira 2013;33(5):575-580.

Carnaghan RBA. Spinal cord compression in fowls due to spondylitis caused by Staphylococcus pyogenes. Journal of Comparative Pathology 1966;76(1):9-14

Caudry SD, Stanisich VA. Incidence of antibiotic-resistant Escherichia coli associated with frozen chicken carcasses and characterization of conjugative R plasmids derived from such strains. Antimicrobial Agents and Chemotherapy 1979;16(6):701-709.

Cetinkaya Y, Falk P, Mayhall CG. Vancomycin-resistant enterococci. Clinical Microbiology Reviews 2000;13(4):686-707.

Chadfield MS, Christensen JP, Christensen $\mathrm{H}$, Bisgaard M. Characterization of streptococci and enterococci associated with septicaemia in broiler parents with a high prevalence of endocarditis. Avian Pathology 2004;33(6):610-617. 
Cobb. Cobb500: broiler performance \& nutrition supplement. São José do Rio Preto; 2015 [cited 2016 Jan 11]. Available from: http://www.cobbvantress.com/docs/default-source/cobb-500-guides/Cobb500_Broiler_ Performance_And_Nutrition_Supplement.pdf

Creti R, Imperi M, Bertuccini L, Fabretti F, Orefici G, Di Rosa R, Baldassarri L. Survey for virulence determinants among Enterococcus faecalis isolated from different sources. Journal of Medical Microbiology 2004;53(1):13-20.

Devriese LA, Cauwerts K, Hermans K, Wood AM. Enterococcus cecorum septicemia as a cause of bone and joint lesions resulting in lameness in broiler chickens. Vlaams Diergeneeskundig Tijdschrift 2002;71(3):219221.

Devriese LA, Hommez J, Wijfels R, Haesebrouck F. Composition of the enterococcal and streptococcal intestinal flora of poultry. Journal of Applied Bacteriology 1991;71(1):46-50.

Dho-Moulin M, Fairbrother JM. Avian pathogenic Escherichia coli (APEC). Veterinary Research 1999;30(2-3):299-316.

Dinev I. Clinical and morphological investigations on the prevalence of lameness associated with femoral head necrosis in broilers. British Poultry Science 2009;50(3):284-290.

Dinev I. Pathomorphological investigations on the incidence of axial skeleton pathology associated with posterior paralysis in commercial broiler chickens. Poultry Science 2013;50(4):283-289.

Dinev I. Pathomorphological investigations on the incidence of clinical spondylolisthesis (kinky back) in different commercial broiler strains. Revue de MédecineVétérinaire 2012;163(11):511-515.

Dolka B, Chrobak-Chmiel D, Makrai L, Szeleszczuk P. Phenotypic and genotypic characterization of Enterococcus cecorum strains associated with infections in poultry. BMC Veterinary Research 2016;12:129.

Droual R, Bickford AA, Farver TB. Scoliosis and tibiotarsal deformities in broiler chickens. Avian Diseases 1991;35(1): 23-30.

Droual R, Chin RP, Rezvani M. Synovitis, osteomyelitis, and green liver in turkeys associated with Escherichia coli. Avian Diseases 1996;40(2):417424.

Ewers C, Janssen T, Kiessling S, Philipp HC, Wieler LH. Molecular epidemiology of avian pathogenic Escherichia coli (APEC) isolated from colisepticemia in poultry. Veterinary Microbiology 2004;104(1-2):91101.

Foulquié-Moreno MR, Sarantinopoulos P, Tsakalidou E, De Vuyst L. The role and application of enterococci in food and health. International Journal of Food Microbiology 2006;106(1):1-24

Franz CMAP, Huch M, Abriouel H, Holzapfel W, Gálvez A. Enterococci as probiotics and their implications in food safety. International Journal of Food Microbiology 2011;151(2):125-140

Gingerich EN, Barnes JH, Owen RL, Rankin SC. Spinal abscesses due to Enterococcus cecorum in broiler chickens: an emerging disease? Proceedings of the American Association of Avian Pathologists; 2009; Seattle. USA: American Association of Avian Pathologists; 2009.

Hayes JR, English LL, Carter PJ, Proescholdt T, Lee KY, Wagner DD, http:// www.ncbi.nlm.nih.gov/pubmed/?term=White\%20DG\%5BAuthor $\% 5 D \&$ cauthor=true\&cauthor_uid=14660361 et al. Prevalence and antimicrobial resistance of enterococcus species isolated from retail meats. Applied Environmental Microbiology 2003;69(12):7153-7160.

Herdt P, Defoort P, Van Steelant J, Swam H, Tanghe L, Van Goethem S, et al. Enterococcus cecorum osteomyelitis and arthritis in broiler chickens. Vlaams Diergeneeskundig Tijdschrift 2009;78(1):44-48.
Heuer OE, Hammerum AM, Collignon P, Wegener HC (2006). Human health hazard from antimicrobial-resistant enterococci in animals and food. Clinical Infectious Diseases 2006;43(7):911-916

Holtom PD, Zamorano D, Patzakis MJ. Osteomyelitis attributable to vancomycin-resistant enterococci. Clinical Orthopaedics and Related Research 2002;(403):38-44.

Jackson CR, Fedorka-Cray PJ, Barrett JB. Use of a Genus- and SpeciesSpecific Multiplex PCR for Identification of enterococci. Journal of Clinical Microbiology 2004;42(8):3558-3565.

Jung A, Martin M, Ryl IM. Comparison of pathogenic and non-pathogenic Enterococcus cecorum strains from different animal species. BMC Microbiology 2017;17(1):33.

Jung A, Rautenschlein S. Comprehensive report of an Enterococcus cecorum infection in a broiler flock in Northern Germany. BMC Veterinary Research 2014;10:311

Kense MJ, Landman WJM. Enterococcus cecorum infections in broiler breeders and their offspring: molecular epidemiology. Avian Pathology 2011;40(6):603-612.

Kola A, Schwab F, Barwolff S, Eckmanns T, Weist K, Dinger E, Klare I, et al. Is there an association between nosocomial infection rates and bacterial cross transmissions? Critical Care Medicine 2010;38(1):46-50.

Kolbjørnsen $\varnothing$, David B, Gilhuus M. Bacterial osteomyelitis in a 3-weekold broiler chicken associated with Enterococcus hirae. Veterinary Pathology 2011;48(6):1134-1137.

Luna LG. Manual of histologic staining methods of the Armed Forces Institute of Pathology. $3^{\text {rd }}$ ed. New York: McGraw-Hill; 1968.

Makrai L, Nemes C, Simon A, Ivanics E, Dudás Z, Fodor L, et al. Association of Enterococcus cecorum with vertebral osteomyelitis and spondylolisthesis in broiler parent chicks. Acta Veterinaria Hungarica 2011:59(1):11-21.

Martin B, Garriga M, Hugas M, Aymerich T. Genetic diversity and safety aspects of enterococci from slightly fermented sausages. Journal of Applied Microbiology 2005;98(5):1177-1190.

Martin LT, Martin MP, Barnes HJ. Experimental reproduction of Enterococcal spondylitis in male broiler breeder chickens. Avian Diseases 2011;55(2):273-278

McGaw L. Use of plant-derived extracts and essential oils against multidrug resistant bacteria affecting animal health and production. In: Rai MK, Kon KV, editors. Fighting multidrug resistance with herbal extracts, essential oils and their components. London: Academic Press; 2013. p.191-203.

McNamee PT, Smyth JA. Bacterial chondronecrosis with osteomyelitis ("femoral head necrosis") of broiler chickens: a review. Avian Pathology 2000;29(4):253-270

Nairn ME. Bacterial osteomyelitis and synovitis of the turkeys. Avian Diseases 1973;17(3):504-517.

Nakazato G, Campos TA, Stehling EG, Brocchi M, da Silveira WD. Virulence factors of avian pathogenic Escherichia coli (APEC). Pesquisa Veterinária Brasileira 2009;29(7):479-486.

Robbins KM, Suyemoto MM, Lyman RL, Martin MP, Barnes HJ, Borst LB. An outbreak and source investigation of enterococcal spondylitis in broilers caused by Enterococcus cecorum. Avian Diseases 2012;56(4):768-773.

Ruiz-Moyano S, Martin A, Benito MJ, Aranda E, Casquette R, Cordoba G. Safety and functional aspects of preselected enterococci for probiotic use in Iberian dry-fermented sausages. Journal of Food Science 2009;74(7):M398-404. 
Schat KA, Nair V. Marek's disease. In: Saif YM, Fadly AM, Glisson JR, McDougald LR, Nolan LK, Swayne DE, editors. Diseases of poultry. $12^{\text {th }}$ ed. Ames: Blackwell Publishing; 2008. p. 452-514

Stalker MJ, Brash ML, Weisz A, Ouckama RM, Slavic D. Arthritis and osteomyelitis associated with Enterococcus cecoruminfection in broiler and broiler breeder chickens in Ontario, Canada. Journal of Veterinary Diagnostic Investigation 2010;22(4):643-645.

Stashak TS, Mayhew IG. The nervous system. In :Jennings PB, Saunders WB, editors. The practice of large animal surgery. Philadelphia: WB Saunders; 1984. p.1013-1016

Talebi A, Taifebagherlu J, Sharifi A, Delkhosh-Kasmaie F. Spondylitis in broiler breeder farms in West-Azerbaijan province, Iran: Clinical Report. Veterinary Research Forum 2016;7(4):353-355.

Tankson JD, Thaxton JP,Vizzier-Thaxton Y. Bacteria in heart and lungs of young chicks. Journal of Applied Microbiology 2002;92(3):443-450.

Tannock GW. Normal microflora: an introduction to microbes inhabiting the human body. London: Chapman and Hall;1995.

Thayer SG, Waltman WD, Wages DP.Streptococcus and Enterococcus. In:Saif YM, Fadly AM, Glisson JR, McDougald LR, Nolan LK, Swayne $D E$, editors. Diseases of poultry. $12^{\text {th }}$ ed. Ames: Blackwell Publishing; 2008. p.900-908.

Van Veen L, Dwars RM, Fabri THF. Mycotic spondylitis in broilers caused by Aspergillus fumigatus resulting in partial anterior and posterior paralysis. Avian Pathology 1999;28(5):487-490.
Wages DP. Streptococcosis. In: Swayne DE, Glisson JR, Jackwood MW, Person JE, Reed WM, editors. Isolation and identification of avian pathogens. $4^{\text {th }}$ ed. Kennett Square: American Association of Avian Pathologists; 1998. p. 58-60.

Wedel MJ. Postcranial pneumaticity in dinosaurs and the origin of the avian lung [thesis]. Berkeley (USA): University of California; 2007.

Wideman Jr RF, Hamal KR, Stark JM, Blankenship J, Lester $H$, Mitchell $\mathrm{KN}$, et al. A wire-flooring model for inducing lameness in broilers: Evaluation of probiotics as a prophylactic treatment. Poultry Science 2012;91(4):870-883.

Wideman RF, Prisby RD. Bone circulatory disturbances in the development of spontaneous bacterial chondronecrosis with osteomyelitis: a translational model for the pathogenesis of femoral head necrosis. Frontiers in Endocrinology 2013;3:1-14

Willems RJL, Bonten MJM. Glycopeptide-resistant enterococci: deciphering virulence, resistance and epidemicity. Current Opinion in Infectious Diseases 2007;20(4):384-390.

Wisplinghoff $H$, Bischoff T, Tallent SM, Seifert H, Wenzel RP, Edmond MB. Nosocomial bloodstream infections in US hospitals: analysis of 24,179 cases from a prospective nationwide surveillance study. Clinical Infectious Diseases 2004;39(3):309-317.

Wood AM, Mackenzie G, Mcgillveray NC, Brown L, Devriese LA, Baele M. Isolation of Enterococcus cecorum from bone lesions in broiler chickens. Veterinary Record 2002;150(1):27. 
